\title{
Preparation of cobalt ferrite nanoparticles using fulvic acid as a capping agent and its effect on catalytic activity
}

\author{
Jinxing LI ${ }^{1}$, Abdelrahman A. Badawy ${ }^{2}$, Guanben DU ${ }^{1}$, Xiaojian ZHOU ${ }^{1 \star}$, Hisham A. Essawy ${ }^{3 *}$ \\ 1 Yunnan Provincial Key Laboratory of Wood Adhesives and Glued Products, Southwest Forestry University, China. \\ 2 Physical Chemistry Department, National Research Centre, 33 El Behooth St., Dokki Giza, Egypt. \\ 3 Department of Polymers and Pigments, National Research Centre, Dokki 12622, Cairo, Egypt.
}

*Corresponding Author: Xiaojian ZHOU, No. 300, Panlong District, Kunming, 650224, China, email: xiaojianzhou@hotmail.com;Hisham Essawy, Egypt Research Center, Cairo, Egypt, email: hishamessawy@yahoo.com

\begin{abstract}
:
Cobalt ferrite was prepared by co-precipitation from cobalt and iron soluble precursors in presence of fulvic acid at different $\mathrm{pH}$ values, namely, 6 and 8 and compared with the same preparation in absence of fulvic acid. The presence of fulvic acid is expected to bind metal ions through bridging before co-precipitation and mineralization. The extent of binding is determined according to the $\mathrm{pH}$ of the process. This influences the mineralization of the resulting cobalt ferrite and the crystallization/ordering of its lattice. In addition, the extent of residual ferric oxide is also a function of the efficiency of binding process. This route of modification for the coprecipitation process was found to be accompanied by enhanced surface area and total pore volume for most of the prepared samples. The involvement of these oxides as catalysts in the photo-catalytic degradation of phenol from wastewater was found to contribute very efficiently and the removal reached about $88 \%$ in some cases, which can be attributed to olation and oxolation process of the formed nanoparticles.
\end{abstract}

Keywords: nanostructured materials; precipitation; oxidation; X-ray diffraction

\section{Introduction}

The surface and catalytic activity of mixed metal oxides are mainly dominated by the methods of preparation and calcination conditions ${ }^{[1-4]}$. Mixed oxides are mostly prepared to merge some properties that cannot be gained from single oxide. The development of new active compounds that can contribute to several fields of applications is a direct result for this merge of properties.

The very attractive properties of nanometric structures derived from metal oxides made them receiving great attention as promising materials for fields such as catalysis and adsorption ${ }^{[4-8]}$. Some reports in the open literature dealt with the adsorption of different dyes to surfaces such as iron oxides ${ }^{[9,10]}$.

Fabrication of adsorbents with controlled features like the size and crystallinity is a challenging task. Thus, the preparation procedure can have a major influence in terms of the chemical composition and microstructure. Co-precipitation is a facile method among those that have been employed for preparation of catalysts. It is favored because it leads to homogenous catalysts from the chemical point of view thereby both the surface and bulk of the prepared catalysts can contribute to catalytic course. These advantages made this method widely applicable to catalysts dedicated for performance under high pressure and moderate temperature ${ }^{[1-14]}$. As an example, the ferrites fabricated via the co-precipitation route acquired a non-aggregated and uniform structure [11-20]. Many studies explored the consequence of using some organic compounds on the coprecipitation process of metal ferrites ${ }^{[21-25]}$. Among them, polyvinyl pyrrolidone (PVP) was added as capping agent during the course of coprecipitation of cobalt ferrite ${ }^{[21]}$. Essawy and co-workers ${ }^{[26-28]}$ used fulvic acid in the preparation of polymeric superabsorbents to pass on reinforcement and functionalization to the resulting structures. This provoked elevation of the chemical activity especially the chelation potential ${ }^{[26]}$. The high functionality and elevated binding capacity of fulvic acid to metal ions allowed their role as templates through the synthesis of metal oxides starting from nitrate precursors via coprecipitation ${ }^{[7,8]}$. This progresses via initial coprecipitation in the form of metal hydroxides in existence of fulvic acid and the 
desired oxides are finally obtainedby calcination at high temperatures. Grouping a number of precursors of metal ions in presence of fulvic acid would be expected to result in homogenous metal oxides exhibiting variation in their composition and characteristics ${ }^{[26-28]}$.

Phenol is commonly used as a raw material for the preparation of many products. This includes pesticides, pharmaceutics, resins and many others. Nevertheless, it is toxic, carcinogenic, and non-biodegradable ${ }^{[29-32]}$.

Pollution of water sources became a parallel fact to the numerous industrial activities. This necessitates the great need to take care of these pollutants prior to their transport into plants of wastewater treatment. Highly developed oxidation techniques are suggested deal with the organic contaminants present in water ${ }^{[33,34]}$. Rigorous efforts are devoted to improve these technologies by changing the catalytic system or the oxidizing agent. Nevertheless, using catalysts that belong to oxidizing reagents in liquid phase may elevate this contamination.

The ongoing study is an effort to obtain nanometric mixed metal oxides incorporating iron and cobalt while revealing a wide range of surface characteristics and chemical composition following modified co-precipitation method of nitrate precursors in solution by employing sodium hydroxide in existence of fulvic acid at $\mathrm{pH} 6$ and 8. This is expected to provide control over the rates of coprecipitation and hence changeable mineralization and ordering of the prepared mixed oxides. The use of such metal oxides as advanced oxidants in the solid form to stop any further contamination to the water through their catalytic cycle is also among the purposes of this study. The work will be also extended to their application in the photocatalytic removal of phenol from wastewater.

\section{Experimental}

\subsection{Materials and methods}

Fulvic acid was supplied from Changsha Xian Shan Yuan Agriculture Technology Co., China. Cobalt nitrate and ferric nitrate were purchased from Sigma-Aldrich, Germany. Phenol aqueous solution (80\%, w/w) was obtained from BDH Chemicals, England. Otherwise, the rest were analytical grade chemicals that were used with no further purification.

\subsection{Preparation of metal oxide nanoparticles via copre- cipitation process}

The wet chemical co-precipitation procedure was involved in the preparation of Cobalt ferrite $\left(\mathrm{CoFe}_{2} \mathrm{O}_{4}\right)^{[12]}$. Nitrates of cobalt and iron were dissolved in distilled water at a certain molar ratio $(\mathrm{Fe} / \mathrm{Co}=2)$ while sodium hydroxide solution (1M) was used for the precipitation. The nitrate solutions and sodium hydroxide were mixed in existence of fulvic acid. The mixing was accomplished via drop wise addition from 3 different burettes into a collective vessel containing $1000 \mathrm{~mL}$ distilled water while continuous stirring was kept running. The dropping rate was managed in such a way to keep the $\mathrm{pH}(6$ or 8$)$ and the temperature $\left(70{ }^{\circ} \mathrm{C}\right)$ unchanged during the co-precipitation. The precipitate was rinsed with distilled water several times to get rid of $\mathrm{NO}^{3-}$ and $\mathrm{Na}^{+}$ions. Filtration was undertaken followed by overnight drying at $100{ }^{\circ} \mathrm{C}$. Lattice formation of the oxides was targeted by calcination at $700{ }^{\circ} \mathrm{C}$ for $4 \mathrm{~h}$. Thus, for simplicity, the sample prepared at $\mathrm{pH} 6$ in absence of fulvic acid is denoted as P6 while F6 designates the same when fulvic acid was included in the recipe. Similarly, P8 reveals the coprecipitation performed at $\mathrm{pH} 8$ in absence of fulvic acid whereas F8 indicates the equivalent sample prepared in existence of fulvic acid F8.

\subsection{Measurements}

$\mathrm{X}$-ray diffractograms of the solids obtained by calcination at $700{ }^{\circ} \mathrm{C}$ were collected using Bruker diffractometer (D 8 advance target) with $\mathrm{CuK}_{\alpha}$ secondly monochromator $(\lambda=$ $1.5405 \AA$ ), operated at $40 \mathrm{kV}$ and $40 \mathrm{~mA}$, at a scanning rate of $0.8^{\circ} 2 \theta \mathrm{min}^{-1}$ for phase identification and line broadening. The crystallite size of each phase calculated by Scherrer equation (Eq. 1):

$\mathrm{d}=\mathrm{K} \lambda / \beta_{1 / 2} \cos \theta$

Where $d$ represents the mean crystalline diameter, $\lambda$ is the wavelength of $\mathrm{x}$-rays, $\mathrm{K}$ is the Scherrer constant (0.89), $\beta_{1 / 2}$ is the full width at half maximum (FWHM) of the main peaks of diffraction and $\theta$ is the angle of diffraction.

The morphology and surface structure of the oxides were imaged by JEOL JEM-1230 transmission electron microscope (TEM) coupled with JEOL-SEM scanning electron microscope (SEM) operated at acceleration voltage of $80 \mathrm{kV}$.

The properties of the surface were investigated by undertaking adsorption of nitrogen gas at $350{ }^{\circ} \mathrm{C}$ using Quantochrome AS1WinTM- automated gas-sorption apparatus (USA). The samples were degassed at $200{ }^{\circ} \mathrm{C}$ for $2 \mathrm{~h}$ prior to the adsorption processes then the specific surface area $\left(\mathrm{S}_{\mathrm{BET}}\right)$ was estimated by applying BrunauerEmmett-Teller (BET) equation. On the hand, the pore size distribution was evaluated from the desorption part of the isotherm using the standard method.

The catalytic removal of phenol from wastewater was undertaken by suspending $1 \mathrm{~g}$ of mixed oxide in a glass reactor containing $100 \mathrm{~mL}$ of distilled water and $100 \mathrm{ppm}$ of phenol and immersed in water bath fitted with temperature controller. Shaking on the solution was applied continuously at $150 \mathrm{rpm}$ and $25^{\circ} \mathrm{C}$ for up to $4 \mathrm{~h}$.

For evaluation of the concentrations of residual phenol in wastewater, $5 \mathrm{~mL}$ suspension was withdrawn from the reactor and centrifuged for $10 \mathrm{~min}$ before recording the absorbance was performed at $270 \mathrm{~nm}$ using a calibrated UV-VIS spectrophotometer (UV-VIS-NIR-3101 PC, Shimadzu) ${ }^{[35]}$. The removal efficiency of phenol was assessed as average of three readings and applying Eq. 2:

Removal, \% $=\left(\left(\mathrm{A}^{\circ}-\mathrm{A}\right)\right) /\left(\mathrm{A}^{\circ}\right) \times 100$

Where $A^{\circ}$ and $A$ are the absorbance of the blank and sample, respectively. According to Beer-Lambert's law, $\mathrm{A}^{\circ}$ and $\mathrm{A}$ are proportional to $\mathrm{C}^{\circ}$ and $\mathrm{C}$, which refer to the concentrations of the blank and sample at time $\mathrm{t}^{[35]}$. 


\section{Results and discussion}

The X-ray diffractograms of mixed oxides prepared in presence and absence of fulvic acid before calcination at $700{ }^{\circ} \mathrm{C}$ are displayed in Figure 1 and summarized in Table 1.

Table 1. The effect of fulvic acid on the peak intensity of the main diffraction lines of $\mathrm{Fe}_{2} \mathrm{O}_{3}$ and $\mathrm{CoFe}_{2} \mathrm{O}_{4}$ along with their crystallite size .

\begin{tabular}{ccccc}
\hline & \multicolumn{2}{c}{$\begin{array}{c}\text { Intensity (a.u.) of } \\
\text { diffraction peaks for } \mathrm{Fe}_{2} \mathrm{O}_{3} \\
\text { and } \mathrm{CoFe}_{2} \mathrm{O}_{4}\end{array}$} & \multicolumn{2}{c}{$\begin{array}{c}\text { size of } \mathrm{Fe}_{2} \mathrm{O}_{3} \text { and } \\
\mathrm{CoFe}_{2} \mathrm{O}_{4} \text { Crystallites } \\
\text { (nm) }\end{array}$} \\
\cline { 2 - 5 } & $\mathrm{Fe}_{2} \mathrm{O}_{3}$ & $\mathrm{CoFe}_{2} \mathrm{O}_{4}$ & $\mathrm{Fe}_{2} \mathrm{O}_{3}$ & $\mathrm{CoFe}_{2} \mathrm{O}_{4}$ \\
\hline P6 & 130 & 106 & 93.3 & 72.8 \\
P8 & - & 95.6 & - & 26.5 \\
F6 & - & 66.8 & - & 23.4 \\
F8 & 85.4 & 74.6 & 70.5 & 55.2 \\
\hline
\end{tabular}

It is obvious from Figure 1 that the coprecipitation achieved at pH 6 in absence of fulvic acid (P6) took place with a portion of $\mathrm{Fe}_{2} \mathrm{O}_{3}$ not taking part in the reaction $\left(2 \theta=33^{\circ}\right)$ whereas cobalt ferrite $\left(2 \theta=35^{\circ}\right)$ was the major phase. When fulvic acid was involved in the process (F6), it propagated without formation of $\mathrm{Fe}_{2} \mathrm{O}_{3}$ while at $\mathrm{pH} 8$, in absence of fulvic acid (P8), $\mathrm{CoFe}_{2} \mathrm{O}_{4}$, was born as a sole phase with high crystallinity (95.6 a.u.). Interestingly, at $\mathrm{pH}$ 8 the presence of fulvic acid (F8) led to birth of both $\mathrm{Fe}_{2} \mathrm{O}_{3}$ and $\mathrm{CoFe}_{2} \mathrm{O}_{4}$.

Table 1 signifies that the existence of fulvic acid at $\mathrm{pH}$ 8 (F8) gave rise to formation of nanometric $\mathrm{Fe}_{2} \mathrm{O}_{3}$ as a main component along with $\mathrm{CoFe}_{2} \mathrm{O}_{4}$ that underwent a two-fold increase in the crystallite size $(55.2 \mathrm{~nm})$ in comparison to the same procedure in absence of fulvic acid $(26.5 \mathrm{~nm}, \mathrm{P} 8)$. The increase was accompanied by a visible decline in the crystallinity of $\mathrm{CoFe}_{2} \mathrm{O}_{4}$ (74.6 a.u.).

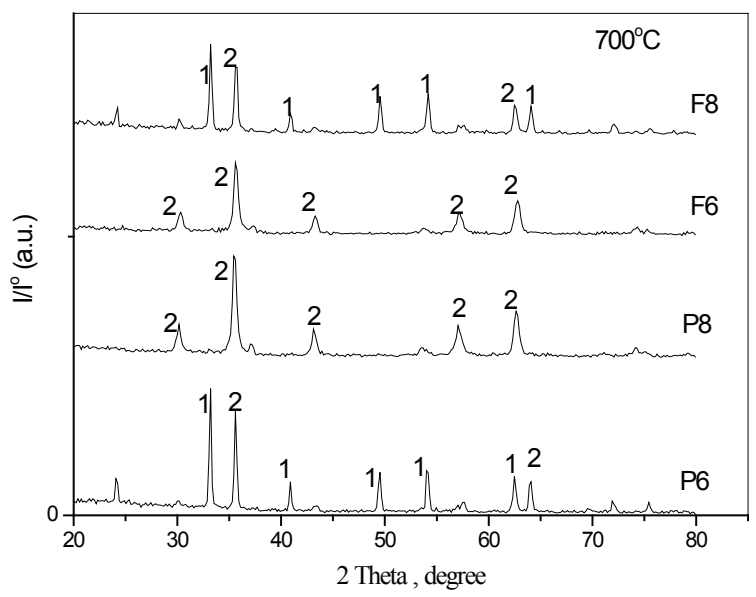

Figure 1.X-ray diffractionprofiles for products of coprecipitations undertaken with and without fulvic acid after calcination at $700{ }^{\circ} \mathrm{C} ; 1$ indicates $\mathrm{Fe}_{2} \mathrm{O}_{3}, 2$ indicates $\mathrm{CoFe}_{2} \mathrm{O}_{4}$.
The observed significant high crystallite size of $\mathrm{CoFe}_{2} \mathrm{O}_{4}$ in case of $\mathrm{F} 6$ might have resulted from a considerable decline in the degree of dispersion of $\mathrm{CoFe}_{2} \mathrm{O}_{4}$ in its crystal lattice [1]. As so, $\mathrm{CoFe}_{2} \mathrm{O}_{4}$ is known with its catalytic activity while in this case the lack of distribution over its crystal lattice is expected to bring about a major drop in its catalytic activity, which was actually the case as will be shown in the next parts.

This could be better understood by the illustration presented in scheme 1 which shows that at $\mathrm{pH} 6$, the fulvic acid present in a protonated form. Thus, the conditions are not appropriate for coordination of $\mathrm{Fe}^{3+}$ and $\mathrm{Co}^{2+}$ by fulvic acid. Opposite trend was encountered at $\mathrm{pH} 8$ in which strong interaction developed between $\mathrm{Fe}^{3+}$ ions and the oxygenated and carboxylate sites. This suggests that this process might be dominated by the tendency of ferric hydroxide to precipitate first, which is harmonizing with the considerable variation in the solubility product values of the hydroxide precursors; $5.92 \times 10^{-15}$ and $2.79 \times 10^{-39}$ for cobalt and ferric ions, respectively. Accordingly, the fulvic acid is thought to have capped the ferric ions while another portion of ferric ions was involved in the construction of the uniformly distributed solid phase ofcobalt ferriteas a result of calcination. During this process the organic material (fulvic acid) has been totally removed by calcination whereas $\mathrm{Fe}_{2} \mathrm{O}_{3}$ developed progressively phase. From Table 1 , we can notice that particle size of $\mathrm{Fe}_{2} \mathrm{O}_{3}$ increases by the presence of fulvic acid. This may be ascribed to many close particles combine together and contribute to the particle size increase by melting of their surfaces ${ }^{[36]}$.
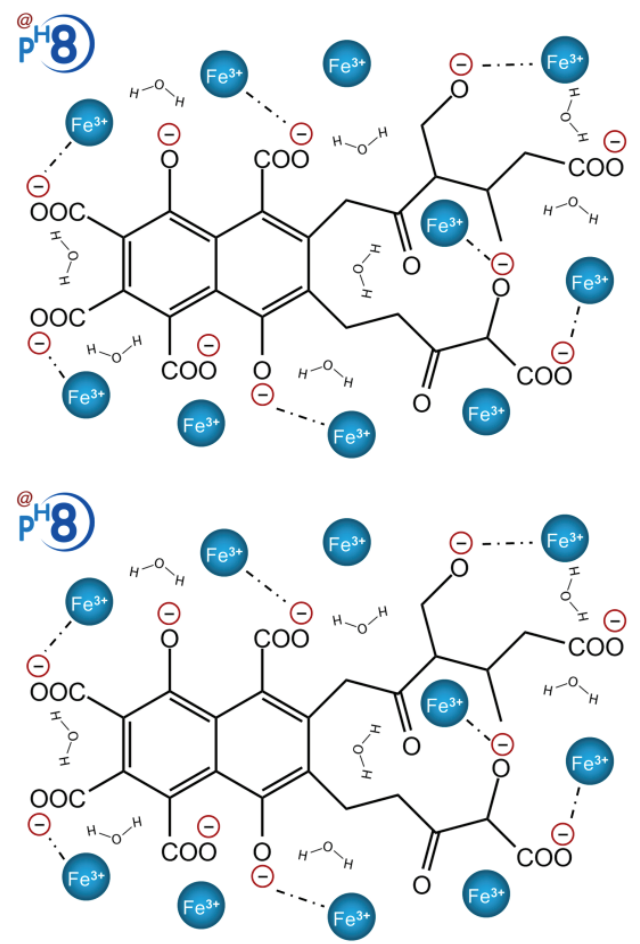

Scheme 1. A suggested mechanism of involving interactions between fulvic acid and ferric ions at $\mathrm{pH} 6$ and 8 prior to calcinations. 
These findings were supported from high resolution transmission electron microscopy images (Figure $2 \mathrm{a}$-d). Figure 2a indicates the presence of two different groups of particles; one exhibits a size of 69-85 $\mathrm{nm}$ while the other one acquired a size between $22-28 \mathrm{~nm}$. The inset of this image confirms that the heterogeneity of the electron diffraction is high which indicates incomplete mineralization of $\mathrm{CoFe}_{2} \mathrm{O}_{4}$ (XRD of P6, Figure 1). On the other hand, Figure $2 \mathrm{c}$ ensures that the presence of fulvic acid (F6) caused drop in the overall crystallinity of the formed $\mathrm{CoFe}_{2} \mathrm{O}_{4}$ despite the complete coprecipitation reaction which leads to effective mineralization. Further, the electron diffraction shows no obvious change in the heterogeneity feature (inset of Figure $2 \mathrm{c}$ ).

Figure $2 \mathrm{~b}, \mathrm{~d}$ gives rise to the interesting feature induced by existence of fulvic acid in the coprecipitation course whereupon the overall ordering became more homogenous (inset of Figure 2d) as compared to the same product in absence of the fulvic acid (inset of Figure 2b). In addition all the formed crystals were in the nanometric scale.

Therefore, it is noticeable that the size of crystallites and of crystallinity degree are very much dependent on the $\mathrm{pH}$ of the medium during precipitation and the presence a capping agent such as fulvic acid. This is in full accordance with earlier studies, which showed that fulvic acid can be involved in different ways during the coprecipitation due to its variable binding potential to metal ions at different $\mathrm{pH}$ values ${ }^{[35,37]}$.
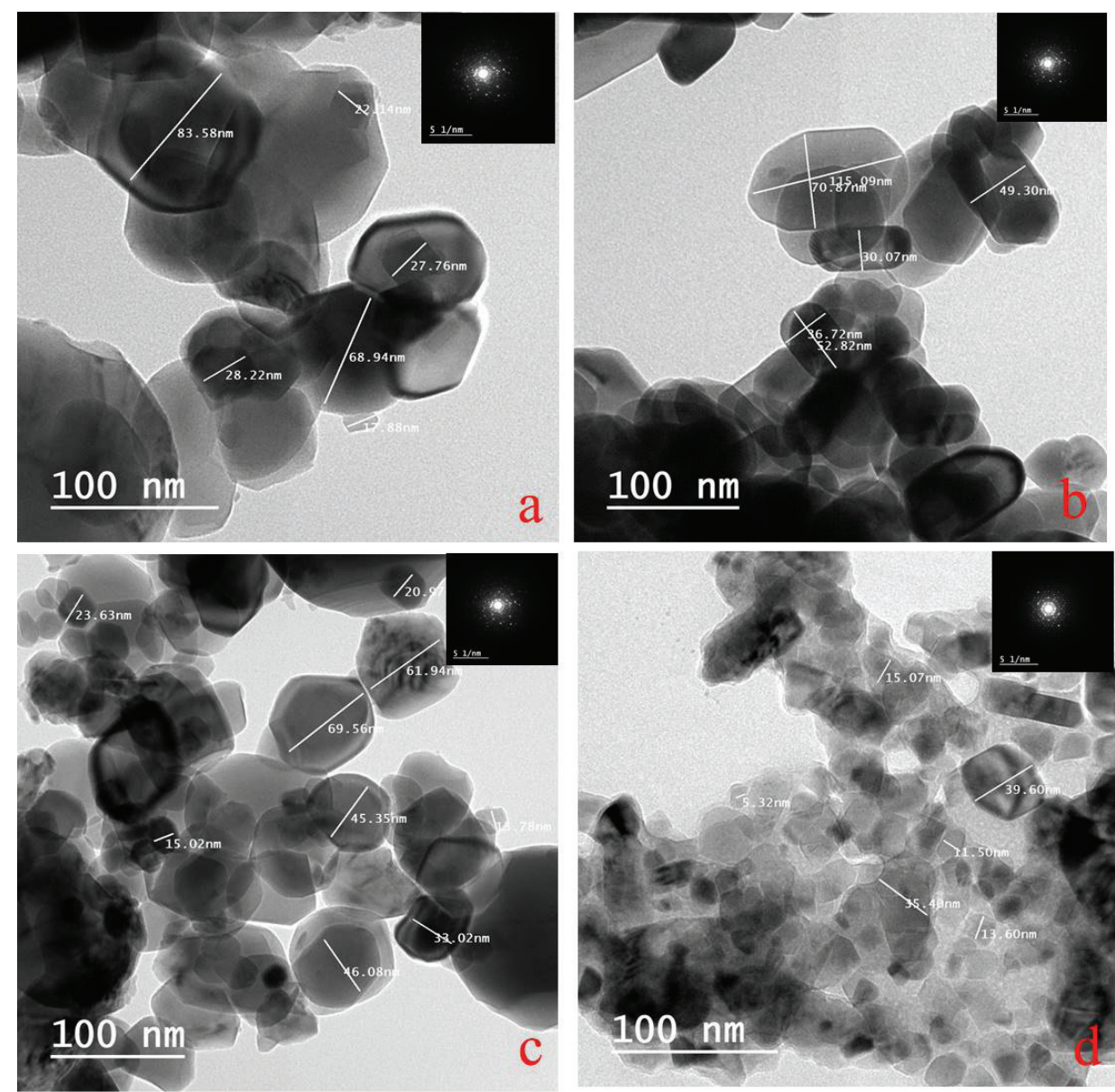

Figure 2. High resolution transmission electron microscopy (HRTEM) imaging of , a: P6, b: P8, c: F6 and d: F8 after calcination at $700^{\circ} \mathrm{C}$.

Table 2. Surface properties of the solids emerged from the various recipes after calcination at $700{ }^{\circ} \mathrm{C}$.

\begin{tabular}{cccc}
\hline Sample & $\mathrm{S}_{\mathrm{BET}}\left(\mathrm{m}^{2} / \mathrm{g}\right)$ & total pore volume $\mathrm{Vp}(\mathrm{cc} / \mathrm{g})$ & mean pore radius $\mathrm{r}(\mathrm{nm})$ \\
\hline P6 & 7.3 & 0.06 & 164.4 \\
P8 & 20.7 & 0.03 & 29.0 \\
F6 & 11.4 & 0.01 & 17.5 \\
F8 & 13.9 & 0.02 & 28.8 \\
\hline
\end{tabular}


Investigation of the surface properties for the prepared solids were accomplished by nitrogen gas adsorptiondesorption as clear from Figure 3 and Table 2. It can be easily recognized that the involvement of fulvic acid at $\mathrm{pH} 6$ (F6) caused a substantial increase in $\mathrm{S}_{\mathrm{BET}}(56 \%)$ as compared to P6. This can be accounted for by the associated drop in $\mathrm{r}$
(Table 2). On the other hand, the practical decrease of $\mathrm{S}_{\mathrm{BET}}$ in existence of fulvic at $\mathrm{pH} 8$ (F8) in comparison with $\mathrm{P} 8$, in which the fulvic acid was absent, can be justified by the domination of the increase in the crystallite size of $\mathrm{CoFe}_{2} \mathrm{O}_{4}$ (Table 1)
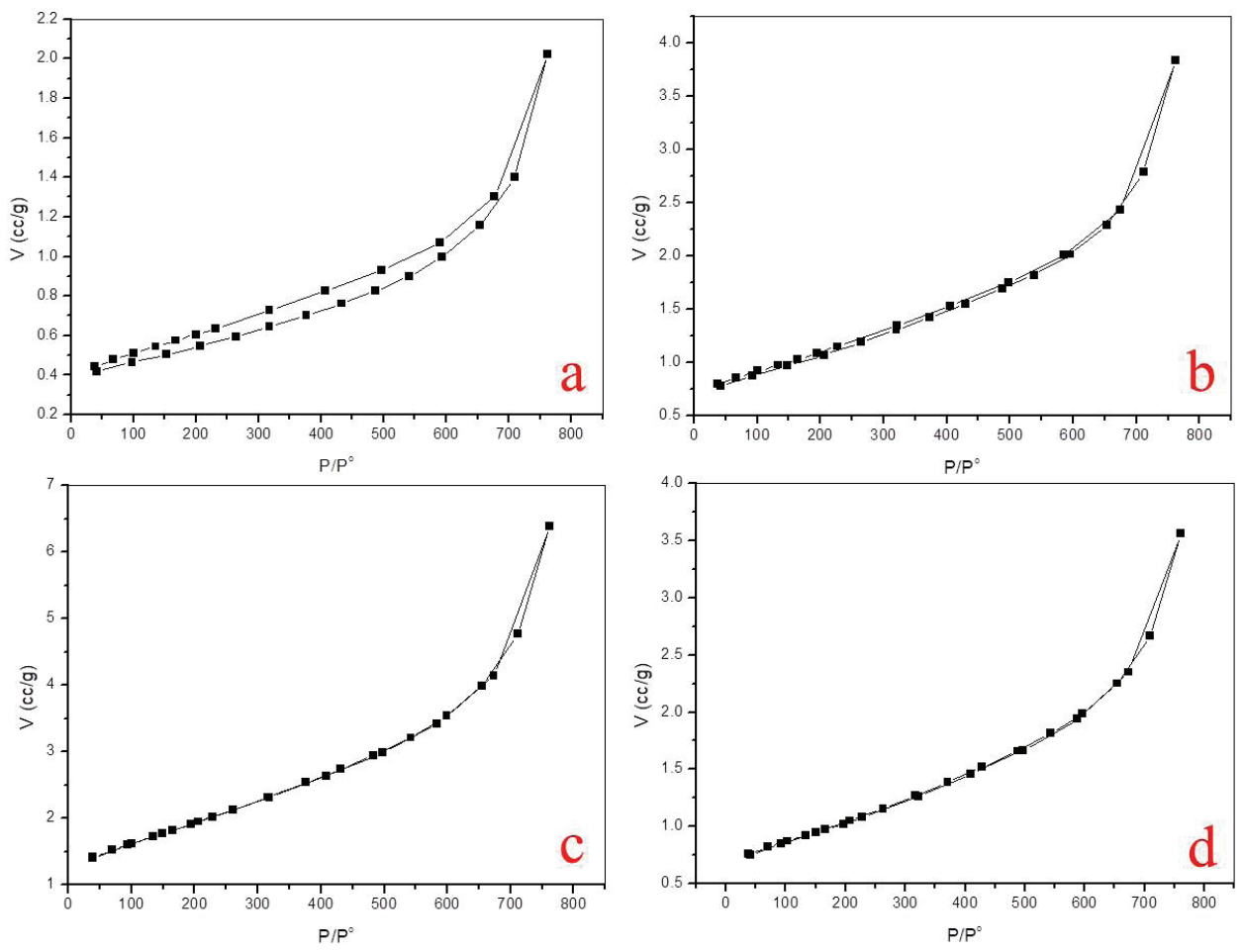

Figure 3. Corresponding nitrogen gas adsorption-desorption isotherms for the solids obtained bycalcination at 700 ${ }^{\circ} \mathrm{C}$; a:P6, b: P8, c:F6 and d: F8.

This was motivating for us to carry out a preliminary photocatalytic study and employ the prepared metal oxides as catalysts during the photocatalytic degradation of phenol present in wastewater. Fig. 4 demonstrates an interesting catalytic action that increases progressively with the time and reaches $88 \%$ and $75 \%$ after $3 \mathrm{~h}$ in case of $\mathrm{F} 8$ and $\mathrm{P} 6$, respectively. The catalytic efficiency can be arranged in the following order: F8 $>$ P6 $>$ P8 $>$ F6. The elevated catalytic activity of $\mathrm{F} 8$ and $\mathrm{P} 6$ with respect to the other formulations (P8 and F6) can be explained by a joint catalytic action of $\mathrm{CoFe}_{2} \mathrm{O}_{4}$ and $\mathrm{Fe}_{2} \mathrm{O}_{3}$, which was not the case for P8 and F6. This may refer to enhancement of the catalytic power of $\mathrm{CoFe}_{2} \mathrm{O}_{4}$ by $\mathrm{Fe}_{2} \mathrm{O}_{3}$. This behavior might be attributed to olation of both metal ions in the form of hydroxides that could be survived during the calcination process. The olation-based structure exhibited oxolation during their employment in photocatalytic reactions which provides hydrogen ions that are able to combine with the phenol and causes its degradable as shown in scheme $2^{[38-41]}$.

$\begin{aligned} {\left[\mathrm{M}\left(\mathrm{H}_{2} \mathrm{O}\right)_{5} \mathrm{OH}\right]^{2+}+\left[\mathrm{M}\left(\mathrm{H}_{2} \mathrm{O}\right)_{6}\right]^{3+} } & \rightleftharpoons\left\{\mathrm{M}\left(\mathrm{H}_{2} \mathrm{O}\right)_{5}(\mu-\mathrm{OH}) \mathrm{M}\left(\mathrm{H}_{2} \mathrm{O}\right)_{5}\right\}^{5+}+\mathrm{H}_{2} \mathrm{O} \\ \left\{\left[\mathrm{M}\left(\mathrm{H}_{2} \mathrm{O}\right)_{5}\right]_{2}(\mu-\mathrm{OH})\right\}^{5+} & \rightleftharpoons\left\{\left[\mathrm{M}\left(\mathrm{H}_{2} \mathrm{O}\right)_{5}\right]_{2}(\mu-\mathrm{O})\right\}^{4+}+\mathrm{H}^{+}\end{aligned}$

Scheme 2. Chemical reactions illustrating the formation of olation-oxolation structure.

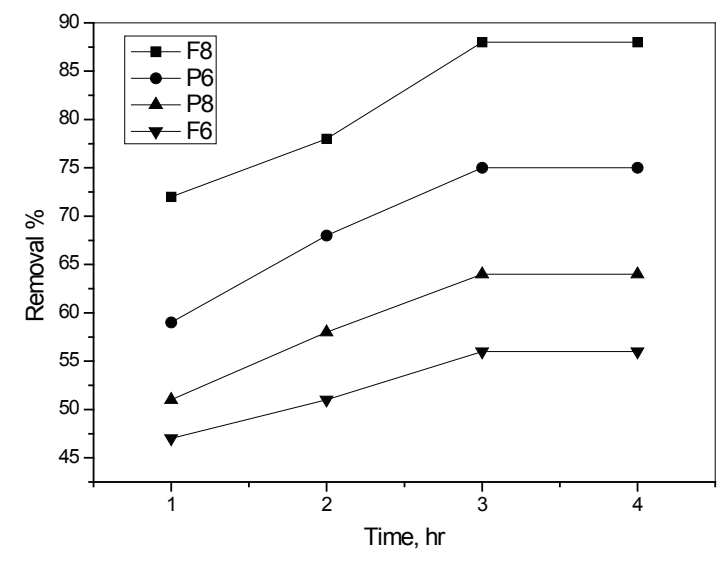

Figure 4. Photocatalytic removal efficiency of phenol using metal oxides prepared by calcination at $700^{\circ} \mathrm{C}$.

\section{Conclusions}

Highly ordered cobalt ferrite can be prepared by modified coprecipitation process starting from cobalt nitrate and ferric nitrate in existence of fulvic acid at different $\mathrm{pH}$ 
values. Fulvic acid exhibits high coordination potential to the starting metal ions during the co-precipitation process. This provides control over the extent of mineralization and the crystallization/ordering of the resulting cobalt ferrite lattice. The control over the co-precipitation can contribute efficiently to the surface area and porosity which made these mixed oxides liable for catalytic applications. The use of the different forms of these oxides as catalysts in the photocatalytic degradation of phenol present in wastewater gives pronouncing levels of removal which reached $88 \%$. This can be accounted for by enhancement of the photocatalytic activity as a result of combination of cobalt ferrite and ferric oxide in a structure exhibiting olation and oxolation.

Author Contributions: Jinxing LI and Dr. Abdelrahman A. Badawy as first author contributed equally to this work, finalize the experiment and gave the ideas. Prof. Xiaojian Zhou and Prof. Hisham A. Essawy, both are the responding author, responsible for whole manuscript.

Acknowledgment: The authors highly appreciate "Yunnan Provincial Reserve Talents for Middle \& Young Academic and Technical Leaders (2019HB026)" and "Ten-thousand Program"-youth talent support program", and the financial support from the administration of the National Research Centre- Egypt, as well as grant No.111814.

\section{References}

[1] El-Shobaky GA, El-Shobaky HG, Badawy AA. Mohamed $\mathrm{GM}$, Effect of $\mathrm{Li}_{2} \mathrm{O}$-doping on physicochemical, surface and catalytic properties of nanosized CuO- $\mathrm{Mn}_{2} \mathrm{O}_{3} /$ cordierite system. Materials Chemistry and Physics 2002; 136(2-3):1143-1147.

[2] El-Shobaky GA, El-Shobaky HG, Badawy AA et al. Physicochemical, surface and catalytic properties of nanosized copper and manganese oxides supported on cordierite. Applied Catalysis A: General 2011; 409:234238.

[3] Badawy AA, Ibrahim ShM. The influence of $\mathrm{La}_{2} \mathrm{O}_{3}$-doping on structural, surface and catalytic properties of nanosized cobalt-manganese mixed oxides. International Journal of Industrial Chemistry 2016;7(3):287-296.

[4] Reddy LH, Arias JL, Nicolas J. et al. Magnetic nanoparticles: design and characterization, toxicity and biocompatibility, pharmaceutical and biomedical applications. Chemical Reviews 2012; 112(11):58185878.

[5] Huggins FE, Bali S, Huffman, GP et al. Iron-oxide aerogel and xerogel catalyst formulations: Characterization by $57 \mathrm{Fe}$ Mössbauer and XAFS spectroscopies. Spectrochimica Acta Part A: Molecular and Biomolecular Spectroscopy 2010; 76(1):74-83.

[6] Zhong, D.K., Sun, J.W., Inumaru, H., Gamelin, D.R., 2009. Solar water oxidation by Composite Catalyst/ $\alpha-\mathrm{Fe}_{2} \mathrm{O}_{3}$ Photoanodes. Journal of the American Chemical Society,
131(17), pp. 6086-6087.

[7] Zhang YZ, He HP, Ye ZZ, et al. Preparation and photoluminescent properties of p-type Li-doped ZnMgO thin films. Materials Letters 2008; 62(8-9):1418-1420.

[8] Tang H, Zhou WJ, Lu A, et al. Characterization of new sorbent constructed from $\mathrm{Fe}_{3} \mathrm{O}_{4}$ /chitin magnetic beads for the dynamic adsorption of $\mathrm{Cd}^{2+}$ ions. Journal of Materials Science 2014; 49(1):123-133.

[9] Mahapatra A, Mishra BG, Hota G. Adsorptive removal of Congo red dye from wastewater by mixed iron oxidealumina nanocomposites. Ceramics International 2013; 39(5):5443-5451.

[10] Zhang X, Zhang PY, Wu Z. Adsorption of methylene blue onto humic acid-coated $\mathrm{Fe}_{3} \mathrm{O}_{4}$ nanoparticles. Colloids and Surfaces A: Physicochemical and Engineering Aspects 2013; 435:85-90.

[11] Kumar P, Sharma SK, Knobel M. et al. Effect of $\mathrm{La}^{3+}$ doping on the electric, dielectric and magnetic properties of cobalt ferrite processed by co-precipitation technique. Journal of Alloys and Compounds 2010; 508(1):115-118.

[12] Fagal GA, Badawy AA, Hassan NA. et al. Effect of $\mathrm{La}_{2} \mathrm{O}_{3}$ treatment on textural and solid-solid interactions in ferric/cobaltic oxides system. Journal of Solid State Chemistry 2012; 194:162-167.

[13] Khandekar MS, Kambale RC, Patil JY, et al. Effect of calcination temperature on the structural and electrical properties of cobalt ferrite synthesized by combustion method. Journal of Alloys and Compounds 2011; 509(5):1861-1865.

[14] Zhou J, Ma J, Sun C, et al. Low temperature synthesis of $\mathrm{NiFe}_{2} \mathrm{O}_{4}$ by a hydrothermal method. Journal of the American Ceramic Society 2005; 88(12):3535-3537.

[15] Peng L, Qin P, Lei $\mathrm{M}$, et al. Modifying $\mathrm{Fe}_{3} \mathrm{O}_{4}$ nanoparticles with humic acid for removal of Rhodamine $B$ in water Journal of Hazardous Materials 2012; 209:193-198.

[16] Illés E, Tombácz E. The effect of humic acid adsorption on $\mathrm{pH}$-dependent surface charging and aggregation of magnetite nanoparticles. Journal of Colloid and Interface Science 2006; 295(1):115-123.

[17] Mondal S, Methods of dye removal from dye house effluent-an overview. Environmental Engineering Science 2008; 25(3): 383-396.

[18] Berneth H, Azine Dyes. Ullmann's Encyclopedia of Industrial Chemistry 2005.

[19] Program NT, Toxicology and carcinogenesis studies of methylene blue trihydrate (Cas No. 7220-79-3) in F344/N rats and B6C3F1 mice (gavage studies). National Toxicology Program Technical Report Series 2008; 540:1.

[20] Sharma YC, Uma Upadhyay SN, An economically viable removal of methylene blue by adsorption on activated carbon prepared from rice husk. The Canadian Journal of Chemical Engineering 2011; 89(2):377-383.

[21] Naseri MG, Saion EB, Ahangar HA, et al. Simple synthesis 
and characterization of cobalt Ferrite nanoparticles by a thermal treatment method. Journal of Nanomaterials 2010; 75:1-8.

[22] Calero-Ddelc VL, Rinaldi C. Synthesis and magnetic characterization of cobalt-substituted ferrite $\left(\mathrm{CoxFe}_{3}-\right.$ $\mathrm{xO}_{4}$ ) nanoparticles. Journal of Magnetism and Magnetic Materials 2007; 314(1):60-67.

[23] Chen L, Shen Y, Bai J. Large-scale synthesis of uniform spinel ferrite nanoparticles from hydrothermal decomposition of trinuclear heterometallic oxocentered acetate clusters. Materials Letters 2009; 63(12):1099-1101.

[24] Zarnega Z, Safari J. Modified chemical coprecipitation of magnetic magnetite nanoparticles using lineardendritic copolymers. Green Chemistry Letters and Reviews 2017; 10(4):235-240.

[25] Gharagozlou M. Synthesis, characterization and influence of calcination temperature on magnetic properties of nanocrystalline spinel Co-ferrite prepared by polymeric precursor method. Journal of Alloys and Compounds 2009; 486(1-2):660-665.

[26] Essawy HA, Mohamed MF, Ammar NS, et al. Potassium fulvate-functionalized graft copolymer of polyacrylic acid from cellulose as a promising selective chelating sorbent. RSC Advances 2017; 7(33):20178-20185.

[27] Mohamed MF, Essawy HA, Ammar NS, et al. Potassium fulvate-modified graft copolymer of acrylic acid onto cellulose as efficient chelating polymeric sorbent. International Journal of Biological Macromolecules 2017; 94:771-780.

[28] Essawy HA, Mohamed MF, Ammar NS, et al. The promise of a specially-designed graft copolymer of acrylic acid onto cellulose as selective sorbent for heavy metal ions. International Journal of Biological Macromolecules 2017; 103:261-267.

[29] Park Y, Ayoko GA, Kurdi R, et al. Adsorption of phenolic compounds by organoclays: Implications for the removal of organic pollutants from aqueous media. Journal of Colloid and Interface Science 2013; 406:196-208.

[30] Amin NAS, Akhtar J, Rai HK. Screening of combined zeolite-ozone system for phenol and COD removal. Chemical Engineering Journal 2010; 158(3):520-527.

[31] Hsu YC, Chen JH, Yang HC. Calcium enhanced COD removal for the ozonation of phenol solution, Water Research 2007; 41(1):71-78.

[32] Busca G, Berardinelli S, Resini C, et al. Technologies for the removal of phenol from fluid streams: A short review of recent developments. Journal of Hazardous Materials 2008; 160(2-3):265-288.

[33] AbdelRehim MH, El-Samahy MA, Badawy AA, et al. Photocatalytic activity and antimicrobial properties of paper sheetsmodified with $\mathrm{TiO}_{2} /$ sodium alginate nanocomposites. Carbohydrate Polymers 2016; 148:194-199.

[34] Ghanem AF, Badawy AA, Ismail N, et al. Photocatalytic activity of hyperbranched polyester/ $/ \mathrm{TiO}_{2}$ nanocomposites. Applied Catalysis A: General 2014; 472:191-197.

[35] Xie J, Meng W, Wu D, et al. Removal of organic pollutants by surfactant modified zeolite: Comparison between ionizable phenolic compounds and non-ionizable organic compounds. Journal of Hazardous Materials 2012; 231-232:57-63.

[36] Mikutta C, Kretzchemar R. Synthetic coprecipitates of exopoly-saccharides and ferrihydrite. Part II: Siderophore-promoted dissolution. Geochimica et Cosmochimica Acta 2008; 72(4):1128-1142.

[37] Yang R, Li Z, Huang B, et al. Effects of Fe(III)-fulvic acid on $\mathrm{Cu}$ removal via adsorption versus coprecipitation. Chemosphere 2018; 197:291-298.

[38] Pechenyuk SI, Semushin VV, Kashulina TG. Aging of oxyhydroxide sorbents saturated with the cations of nonferrous metals. Chemistry for Sustainable Development 2003; (11): 627-633.

[39] Jiang L, Mao X. Degradation of phenol-containing wastewater using an improved electro-fenton process. International Journal of Electrochemical Science 2012; 7:4078-4088.

[40] Qu Y, Yang H, Yang N, et al. The effect of reaction temperature on the particle size, structure and magnetic properties of coprecipitated $\mathrm{CoFe}_{2} \mathrm{O}_{4}$ nanoparticles. Materials Letters 2006; 60(29-30):3548-3552.

[41] Marques Neto JO, Bellato CR, de Souza CHF, et al. Synthesis, Characterization and Enhanced Photocatalytic Activity of Iron Oxide/Carbon Nanotube/Ag-doped $\mathrm{TiO}_{2}$ Nanocomposites. Journal of the Brazilian Chemical Society 2017; 28(12):2301-2312. 